To take three points specifically: (1) Curriculum Certainly most diseases in tropical countries are "non-tropical," but this should not imply that the spectrum there resembles that in Britain. The diseases are predominantly those of poverty, for whose management a community approach is essential. Is this inculcated in the usual British-oriented school? To take an example: faced with a child suffering from malnutrition the British-trained doctor's response is to admit to hospital and commence milk supplements and vitamins, then discharge the child when improved. The more appropriate response, for which a differently directed training is needed, is to treat mother and child outside hospital in a nutrition rehabilitation centre and, together with agricultural workers, teachers, and others, to attempt to improve the nutritional standards of the area.

(2) Preventive medicine A sharp distinction is drawn between this and curative medicine, the former to be the preserve of public health personnel, the latter that of doctors. Is such a distinction not more likely to lead to the lowering of standards that is suggested, since it will appear that the prestigious doctors are not interested in prevention? Is not an integrated approach more desirable-with auxiliaries at rural level concerned with both prevention and cure, and doctors at district level supervising both? In this capacity the value of the teaching of management in the medical course will be appreciated (and this does not mean the same as administration).

(3) Medical auxiliaries The fear that they will eventually replace doctors will be obviated if co-operation is encouraged by joint activities during training and if the team approach is always promoted.

Medical students in a rich country are being prepared for a situation in which the consultation with a single patient is the ideal. This may happen in developing countries for the few in the cities, and maybe for the majority in the far future; but at present the doctor's main concern in these countries must be for the community, where the needs are the greatest. Education for this approach will not be inferior but may well be different.

TONY WATERSTON

Royal Hospital for Sick Children

Glasgow

\section{Hospitals for the developing world}

SIR,-Your leading article on "Hospitals for the developing world" (8 November, p 309) is excellent. There are some further details which should be considered as priorities.

The under-fives and their mothers will be the most numerous and urgent of those in need of health care and supervision. But there should be no rigid segregation of the under-fives. The success of medical care and supervision is greatly enhanced by continuity-through the age groups (including school age) together with continuity through episodes of sickness and health and continuity through hospital, health centre, and home. Continuity must be encouraged through the maintenance of record cards and through the attention to and the confidence in family care.

The article mentions "a separate health and nutrition rehabilitation unit." These are better not separate but closely annexed to the hospital or health centre, where concontinuous supervisory and education conditions.

Rooming-in for maternity patients is essential and so is, whenever possible, the admission of the mother with the sick child.

However simplistic the conditions may be, the doctor, nurse, or medical auxiliary in charge should learn to use and rely on a microscope.

London SE24

Cicely D Williams

\section{Trainer-teaching techniques}

SIR,-It would be unfortunate if $\mathrm{Dr} C$ Josephs's letter (25 October, p 224), which was almost unreservedly supported by four out of five subsequent letters (8 November, p 348), were allowed to discourage those who organise trainers' courses. It has always been easier to destroy than to build.

Dr Josephs concedes that trainers' courses are necessary, as surely he must, for only the arrogant will presume to teach without first learning how. $\mathrm{He}$ jibs at educational jargon. An educationalist might equally jib at a letter I had today from an ophthalmic surgeon which contained the words "hypermetropic astigmatic error," "exophoria," "amblyopia," and "slowing in her vertebrovascular circulation" in just a few sentences. Words are not necessarily wrong when we do not understand their meaning. The list of jargon he quotes can be translated freely as, "allow the trainee to develop his own potential, don't force your ideas on him, test his progress, and if he is not progressing well you may have to learn from your fellow-teachers to change your teaching methods." Is that not reasonable advice?

He complains also that the plenary sessions invariably failed to reach a conclusion. Vocational training is still in its infancy, and all ideas for improving it are welcome. Is it not better to offer a choice of ideas and methods than to insist "you must do it my way"?

Eastbourne

CW SAVILE

SIR,-Dr C Josephs's letter (25 October, p 224) illustrates three points: (1) that excellent teachers are born, not made, and do intuitively what others have to learn to do; (2) that they, in common with other leaders of the profession, run so fast that they forget to look back to see if the rest of us are following; and (3) that those who learn best from didactic teaching tend to rise high up the professional ladder and then perpetuate those methods which have suited them so well and us so badly.

But it is no good having splendid leaders if nobody follows and it is equally useless having splendid teaching if nothing is learnt. Surely the proof lies in $(a)$ the student's choice of the method, because his approval so greatly affects his learning, and $(b)$ the measurement and assessment of the knowledge, skills, and attitudes acquired during the training period and the years that follow. In contrast to Dr Josephs, on my course of one half-day a week for 30 weeks, I learnt a tremendous amount. Not only a variety of teaching methods (including a judicious use of the didactic method) and the knowledge that I must learn to be flexible to suit the needs of the subject, the trainee, and the trainer, but also a lot of new insight into my own thought processes, attitudes, prejudices, etc. Even if it could be proved that I am no better as a trainer, I would insist that I am a much better doctor as a result of the course.

Perhaps the difference is that Dr Josephs is a giant whereas most of us are not and some of us are even intellectual pygmies. What part the lesser fry should and will have in the vocational training schemes remains to be seen, and even the most devoted enthusiasts of modern methods agree that the case is as yet not completely proved, yet surely all of us should still be capable of learning. If over the years we, the recipients of old-style teaching, have become incapable of continuous and continuing learning is this not the most damning indictment yet of the old didactic system?

Dover

R J L Davis

SIR,-I was very interested to read Dr C Josephs's letter (25 October, p 224). From my own experience as a trainee in 1966-7, I have a great deal of sympathy for him. My trainer was singlehanded, assisted at that time only by a part-time practice nurse, and his teaching technique was simple. He gave me four surgeries and one night duty per week to do, and I also attended the local GP hospital and an industrial rehabilitation unit of which he was unit medical officer. I sat in on surgeries with him for the first few weeks and accompanied him on his visits on the first day. From then on I may have been physically on my own but he was always readily available in the background for advice and assistance.

He did not have the benefit of the present role explosion and had to get along without dynamic ongoing feedback or even total interview programming involvement. If he subscribed to the modern pretence that general practice is a specialty (how can something general be special?) he gave me no indication of so doing. He merely had a powerful and highly infectious enthusiasm for general practice, saying that it was what you made it.

But in that year I learnt at least as much as, if not more than, I had learnt in six years at medical school and two years of house jobs put together.

M G BARLEY

Brighton

Medicine and pharmacy

SIR,-I wish to compile a list of persons with dual qualifications in medicine and pharmacy. The reason is that I am frequently asked to suggest persons for various technical and professional committees, and there are times when it would be most useful to have a person with qualifications in both professions. For example, the Standing Pharmaceutical Advisory Committee consists solely of persons with pharmaceutical qualifications, but we think it useful to have a member also qualified in medicine and have usually appointed someone practising medicine but having a pharmaceutical qualification (not necessarily a registered pharmacist). In this instance a general practitioner 